\title{
Effective Electrochemical Sensor Based on Au Nanoparticles Decorated Carboxylated Multi-wall Carbon Nanotube (AuNPS@c-MWCNTs) Nanocomposites for Determination of Dicapthon Pesticide in Agricultural Food
}

\author{
Lei Wang, Yao Liu, Yufei Chen* \\ School of Cereal, Jilin Business and Technology College, Changchun 130507, China \\ *E-mail: chenyufei202012@ sina.com
}

doi: $10.20964 / 2021.04 .64$

Received: 2 January 2021 / Accepted: 24 February 2021 / Published: 28 February 2021

\begin{abstract}
This study was focused on the preparation and characterization of nanocomposite Au nanoparticles and carboxylated MWCNTs (Au NPs@c-MWCNTs) as electrochemical sensors for determination of dicapthon pesticide in agricultural food samples. Au NPs@c-MWCNTs nanocomposite was electrodeposited on glassy carbon electrode (GCE). The morphology and crystal structure of the modified electrode were characterized by SEM and XRD analyses, which indicated that the spherical $\mathrm{Au}$ NPs in fcc crystal structure were uniformly distributed on inter-connected network-like structure of c-MWCNTs. The electrochemical characterization of bare GCE, MWCNTs/GCE and Au NPs@cMWCNTs/GCE by cyclic voltammetry (CV) and differential pulse voltammetry (DPV) techniques showed that the Au NPs@c-MWCNTs/GCE had more stable, sharp signal toward dicapthon. Au NPs@c-MWCNTs/GCE exhibited excellent selectivity, high stability, the acceptable detection limit $(0.09 \mu \mathrm{g} / \mathrm{l})$ and linear range (0 to $2400 \mu \mathrm{g} / \mathrm{l})$ for determination of dicapthon. The capability of Au NPs@cMWCNTs/GCE was evaluated for dicapthon detection in cabbage as a real sample. The results showed an improvement in electrochemical sensing properties of Au NPs@c-MWCNTs/GCE which can be attributed to the electron-transfer enhancement between analyte and electrode surface due to interface efficiently of MWCNTs and Au NPs and large surface area of Au NPs and their highly conductive nature.
\end{abstract}

Keywords:Nanocomposite; Au nanoparticles; Carboxylated MWCNTs; Electrochemical sensor; Dicapthon; Agricultural food

\section{$\underline{\text { FULL TEXT }}$}

(C) 2021 The Authors. Published by ESG (www.electrochemsci.org). This article is an open access article distributed under the terms and conditions of the Creative Commons Attribution license (http://creativecommons.org/licenses/by/4.0/). 